\title{
Single-session bridge-to-surgery choledochoduodenostomy and duodenal stenting in patient with malignant biliary and duodenal obstruction
}

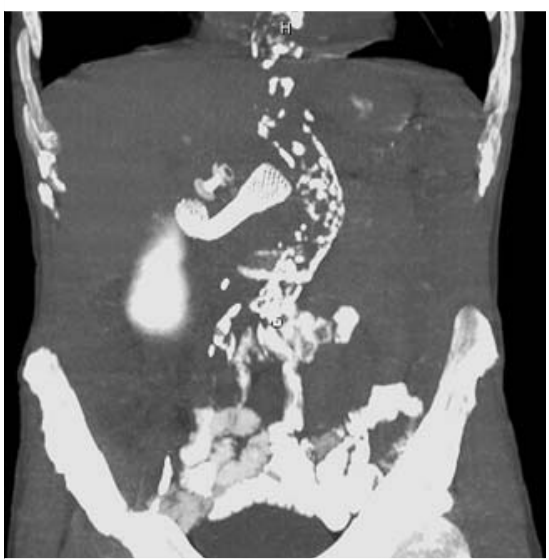

- Fig. 1 Computed tomography scan confirmed correct positioning of both stents.

Endoscopic ultrasound (EUS)-guided biliary drainage using lumen-apposing metal stent (LAMS) is considered an effective alternative approach when endoscopic retrograde cholangiopancreatography fails in patients with malignant obstructive jaundice. Duodenal neoplastic stenosis may coexist and patient management becomes challenging. Sequential placement of biliary and duodenal stents has been described previously in patients with unresectable pancreatic cancer [1]. We report the case of a 73-year-old man affected by obstructive jaundice, cholangitis, and vomiting due to resectable cancer of the pancreatic head. Secondary duodenal infiltration prevented access to the papilla of Vater, and therefore EUSguided choledochoduodenostomy (EUSCD) was performed.

From the duodenal bulb, an $8 \times 8 \mathrm{~mm}$ LAMS (Hot Axios; Boston Scientific, Marlborough, Massachusetts, USA) was directly deployed, and good biliary drainage was obtained. During the same session, an uncovered $60 \times 10 \mathrm{~mm}$ self-expandable metal stent (Wallflex; Boston Scientific) was deployed across the $30 \mathrm{~mm}$ length of the duodenal stenosis, taking care not to dislocate the

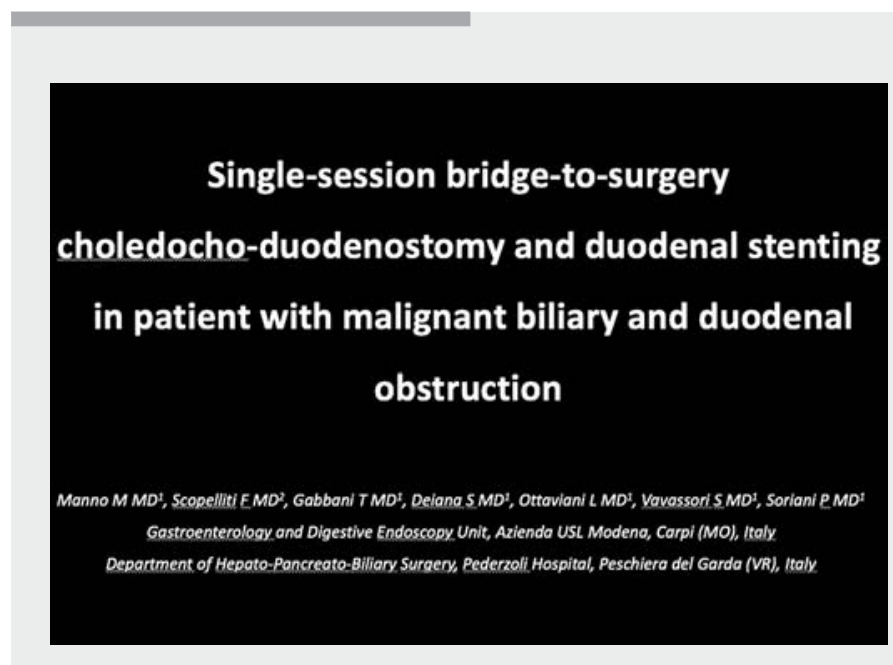

$\checkmark$ Video 1 Single-session bridge-to-surgery choledochoduodenostomy and duodenal stenting in patient with malignant biliary and duodenal obstruction.

LAMS ( Video 1 ). The proximal flange was positioned within the duodenal bulb, adjacent to the LAMS. Subsequent computed tomography scan confirmed the correct position of both stents ( $\triangleright$ Fig. $\mathbf{1}$ ). Jaundice progressively resolved, and the patient restarted oral feeding and was referred to surgery.

The LAMS distal flange was positioned within the common bile duct; therefore, it was possible to easily perform the usual common hepatic duct jejunostomy. The proximal flange of both stents (LAMS and duodenal stent) was located within the duodenal bulb (and not transpylorically). A pylorus-preserving pancreaticoduodenostomy, rather than pylorus-resecting pancreaticoduodenostomy, was therefore performed [2].

In conclusion, even in challenging patients with malignant distal biliary and duodenal obstruction by resectable pancreatic cancer, bridge-to-surgery singlesession EUS-CD and duodenal stenting is feasible and effective. However, attention is required when placing the duodenal stent to avoid LAMS dislocation or compromise further surgical treatment.
Endoscopy_UCTN_Code_TTT_1AO_2AZ

Competing interests

The authors declare that they have no conflict of interest.

The authors

Mauro Manno', Filippo Scopelliti², Tommaso Gabbani ${ }^{1}$, Simona Deiana ${ }^{1}$, Laura Ottaviani ${ }^{1}$, Sara Vavassori' ${ }^{1}$, Paola Soriani ${ }^{1}$

1 Gastroenterology and Digestive Endoscopy Unit, Azienda USL Modena, Carpi, Italy

2 Department of Hepato-Pancreato-Biliary Surgery, Pederzoli Hospital, Peschiera del Garda, Italy

Corresponding author

Mauro Manno, MD

Gastroenterology and Digestive Endoscopy Unit, Azienda USL Modena, Via Guido

Molinari 2, 41012 Carpi (MO), Italy

Fax: +39-059-659250

m.manno@ausl.mo.it 
Bibliography

[1] Anderloni A, Buda A, Carrara S et al. Singlesession double-stent placement in concomitant malignant biliary and duodenal obstruction with a cautery-tipped lumen apposing metal stent. Endoscopy 2016; 48 : E321-E322

[2] Klaiber U, Probst P, Buchler MW et al. Pylorus preservation pancreatectomy or not. Transl Gastroenterol Hepatol 2017; 2: 100
DOI https://doi.org/10.1055/a-1119-0960

Published online: 27.2.2020

Endoscopy 2020; 52: E318-E319

(c) Georg Thieme Verlag KG

Stuttgart · New York

ISSN 0013-726X
ENDOSCOPY E-VIDEOS

https:/|eref.thieme.de/e-videos

回回 Endoscopy E-Videos is a free Fection, reporting 回和: on interesting cases and new techniques in gastroenterological endoscopy. All papers include a high quality video and all contributions are freely accessible online.

This section has its own submission website at

https://mc.manuscriptcentral.com/e-videos 